Check for updates

Cite this: Mater. Adv., 2020 1, 1301

Received 9th June 2020, Accepted 13th July 2020

DOI: $10.1039 / \mathrm{d} 0 \mathrm{ma} 00395 f$

rsc.li/materials-advances

\title{
Universal solid-state oxygen redox in antifluorite lithium oxides via transition metal doping $\dagger$
}

\author{
Hiroaki Kobayashi, (D)*a Tetsuya Makimoto, ${ }^{\mathrm{b}}$ Yoshiyuki Ogasawara, ${ }^{\mathrm{b}}$ \\ Kosuke Harada, ${ }^{\mathrm{b}}$ Masanobu Nakayama, (D) c Mitsuhiro Hibino, ${ }^{\mathrm{b}}$ Tetsuichi Kudo, \\ Noritaka Mizuno ${ }^{\mathrm{b}}$ and Kazuya Yamaguchi (D) ${ }^{\mathrm{b}}$
}

\begin{abstract}
Solid-state oxygen redox can potentially be used in high-capacity cathode materials of lithium-ion batteries. This study demonstrates a reversible solid-state oxygen redox in antifluorite lithium oxide via doping of $\mathrm{Ni}$. Ni-Doping of $\mathrm{Li}_{2} \mathrm{O}$ enables the reversible redox reaction of $\mathrm{O}^{2-} / \mathrm{O}_{2}{ }^{2-}$ in addition to the transition metal redox, with a reversible capacity of $270 \mathrm{~mA} \mathrm{~h} \mathrm{~g}^{-1}$. The $\mathrm{O} \mathrm{K}$-edge $\mathrm{X}$-ray absorption spectroscopy reveals that the solid-state oxygen redox reaction is universal in transition metal dopants, which are probably activated by the $2 p$ electron holes in $O$ that are formed via hybridization with $d$ orbitals of the transition metal. Considering the cathode performances and earth abundance of dopant transition metals, $\mathrm{Ni}$-doping of $\mathrm{Li}_{2} \mathrm{O}$ effectively leads to the development of high-capacity cathode materials.
\end{abstract}

\section{Introduction}

High-performance lithium-ion batteries (LIBs) are attractive choices for stationary storage applications because of their high energy density and specific capacity. Enhancing the energy densities of the cathodes in LIBs by utilizing the redox reactions of oxide ions in cathode materials has recently attracted extensive attention. ${ }^{1-5}$ For instance, Li-rich layered rocksalts $\left(\mathrm{Li}_{2} \mathrm{MnO}_{3}{ }^{6-12}\right.$ $\mathrm{Li}_{2} \mathrm{RuO}_{3},{ }^{13-15} \mathrm{Li}_{2} \mathrm{IrO}_{3},{ }^{16-18}$ and their solid solutions with $\mathrm{LiTMO}_{2}$ (TM: transition metal) $\left.{ }^{19-23}\right)$, disordered rocksalts $\left(\mathrm{Li}_{3} \mathrm{NbO}_{4^{-}}\right.$ $\mathrm{LiTMO}_{2},{ }^{24} \mathrm{Li}_{2} \mathrm{TiO}_{3}-\mathrm{LiTMO}_{2},{ }^{25}$ and $\mathrm{Li}_{4} \mathrm{Mn}_{2} \mathrm{O}_{5}{ }^{26,27}$ ), and antifluorites $\left(\mathrm{Li}_{5} \mathrm{FeO}_{4},{ }^{28-37} \mathrm{Li}_{6} \mathrm{CoO}_{4},{ }^{28,38}\right.$ and $\left.\mathrm{Li}_{5} \mathrm{AlO}_{4}{ }^{39,40}\right)$ facilitate an increase in capacity by using partial oxygen redox along with transition metal redox. Among them, antifluorite $\mathrm{Li}_{2} \mathrm{O}$ exhibits the highest possible theoretical capacity of $897 \mathrm{~mA} \mathrm{~h} \mathrm{~g}^{-1}$, which is based on the solid-state oxygen redox reaction given by

$$
2 \mathrm{Li}_{2} \mathrm{O} \rightleftarrows \mathrm{Li}_{2} \mathrm{O}_{2}+2 \mathrm{Li}^{+}+2 \mathrm{e}^{-}
$$

$\mathrm{Li}_{2} \mathrm{O}$ and $\mathrm{Li}_{2} \mathrm{O}_{2}$ demonstrate low electrochemical activities and poor electric conductivities. However, metal/metal oxide compositions (i.e., $\mathrm{Co}_{3} \mathrm{O}_{4}, \mathrm{Ru}$, and $\mathrm{Ir}$ ) can activate $\mathrm{Li}_{2} \mathrm{O}$ to enable the forward reaction. ${ }^{4-45}$ These composite cathodes

\footnotetext{
${ }^{a}$ Institute of Multidisciplinary Research for Advanced Materials, Tohoku University, 2-1-1 Katahira, Aoba-ku, Sendai, Miyagi, 980-8577, Japan.

E-mail: h.kobayashi@tohoku.ac.jp

${ }^{b}$ Department of Applied Chemistry, School of Engineering, The University of Tokyo,

7-3-1 Hongo, Bunkyo-ku, Tokyo, 113-8656, Japan

${ }^{c}$ Department of Advanced Ceramics, Nagoya Institute of Technology, Gokiso,

Showa, Nagoya, Aichi, 466-8555, Japan

$\dagger$ Electronic supplementary information (ESI) available. See DOI: 10.1039/d0ma00395f
}

exhibit high capacities and great cyclability; however, they require expensive metal elements with concentrations of more than $20 \mathrm{wt} \%$. Contrarily, metal doping of $\mathrm{Li}_{2} \mathrm{O}$ effectively utilizes oxygen redox. Previous studies have reported that 5-10 mol\% TM consisting of $\mathrm{Fe},{ }^{46} \mathrm{Co},{ }^{47-52} \mathrm{Cu},{ }^{53} \mathrm{Rh},{ }^{47}$ and $\mathrm{Ir}^{47}$ are substitutionally introduced to the cationic site of $\mathrm{Li}_{2} \mathrm{O}$. The transition metal-doped $\mathrm{Li}_{2} \mathrm{O}$ (TMDL) cathodes exhibit a reversible solid-state oxygen redox reaction, along with a TM dopant redox reaction. When considering the doped TM and assuming that the TM and all oxygen are involved in the redox reaction, the theoretical capacity of TMDL (5- $10 \mathrm{~mol} \%$ ) is $800-880 \mathrm{~mA} \mathrm{~h} \mathrm{~g}^{-1}$. Therefore, TMDL is a promising high-capacity cathode material.

The main role of doped TM is to enhance the conductivity and/or catalytic activity of oxygen because the solid-state oxygen redox reaction does not contain TM. Therefore, the solid-state oxygen redox reaction of TMDL should be independent of dopant elements. Herein, we show a unique cathode material of TMDL doped with $\mathrm{Ni}$ and demonstrate a universal solid-state oxygen redox reaction of TMDL.

\section{Results and discussion}

\section{Effect of Ni-doping to lithium oxide}

Ni-Doping of $\mathrm{Li}_{2} \mathrm{O}$ was conducted using a mechanochemical treatment. The optimized cathode material was prepared using $\mathrm{LiNiO}_{2}$ as a Ni-dopant source with an atomic ratio of $\mathrm{Ni} /(\mathrm{Li}+\mathrm{Ni})=$ $8 \%$ (see Section $\mathrm{S} 1$, ESI $\dagger$ for details).

Fig. 1 shows the X-ray powder diffraction (XRD) pattern of the sample. Broad peaks were attributed to a $\mathrm{Li}_{2} \mathrm{O}$-based 


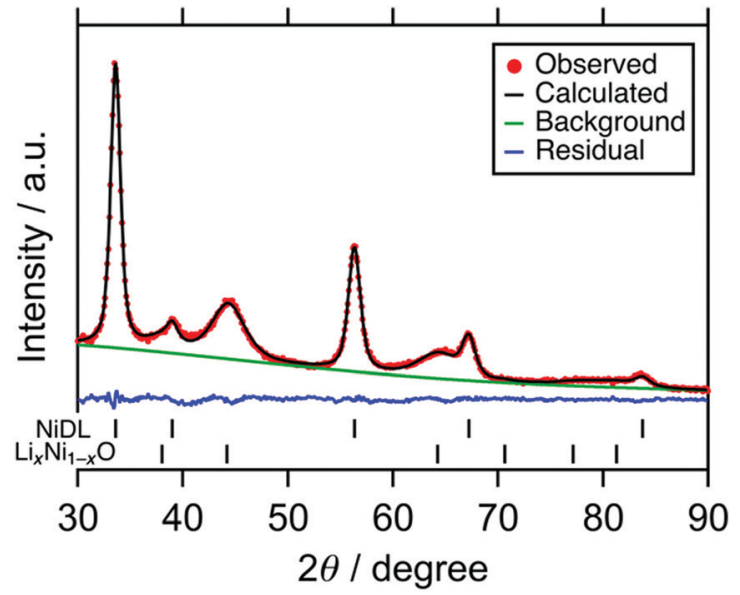

Fig. 1 XRD patterns of NiDL with the fitting curve by Rietveld refinement.

antifluorite and $\mathrm{LiNiO}_{2}$-based phase. The scanning electron microscopy (SEM) images show that aggregation of particles occurs and the particle size is ranged from 1 to $10 \mu \mathrm{m}$ (see Fig. S3, ESI $\dagger$ ). The Ni K-edge XAS analyses show that Ni-doping of the cation site in the $\mathrm{Li}_{2} \mathrm{O}$ structure occurs to form $\mathrm{Ni}$-doped $\mathrm{Li}_{2} \mathrm{O}$ (NiDL, see Section S3, ESI $\dagger$ for details). However, in the $\mathrm{Li}_{2} \mathrm{O}$-based phase, only $1.8 \%$ of the cation site is substituted with $\mathrm{Ni}$ according to the Rietveld refinement (Fig. 1 and Table 1); less Ni-doping occurs compared with Fe-, Co-, or Cu-doping to $\mathrm{Li}_{2} \mathrm{O}$, where $6-8 \%$ of the $\mathrm{Li}_{2} \mathrm{O}$ cation site is substituted by $\mathrm{Fe}$, Co, and $\mathrm{Cu}^{46,49,53}$ This can, probably occur because Ni prefers octahedral coordination over tetrahedral coordination. ${ }^{54}$ The undoped $\mathrm{LiNiO}_{2}$ remains as the $\mathrm{LiNiO}_{2}-$ based phase; in the phase, the main peak of the pristine $\mathrm{LiNiO}_{2}$ at around $18^{\circ}$ almost disappears, while broad peaks at $38^{\circ}, 45^{\circ}$, and $64^{\circ}$ are observed (see Fig. S2a, ESI $\dagger$ ). These peaks are attributable to 111,200 , and 220 reflections of cubic rocksalt $\mathrm{Li}_{x} \mathrm{Ni}_{1-x} \mathrm{O}(x<0.5, F m \overline{3} m$, PDF\#01-081-0095), respectively. Since the hexagonal layered rocksalt $\mathrm{LiNiO}_{2}$ transforms to cubic cation-disordered rocksalt $\mathrm{Li}_{x} \mathrm{Ni}_{1-x} \mathrm{O}$ by the mechanochemical treatment (see the previous literature ${ }^{55}$ and Section S4, ESI $\dagger$ ), the $\mathrm{LiNiO}_{2}$-based phase is attributed to the cubic cation-disordered rocksalt $\mathrm{Li}_{x} \mathrm{Ni}_{1-x} \mathrm{O}$. As a result, the sample is composed of $0.87(1)\left(\mathrm{Li}_{0.947(9)} \mathrm{Ni}_{0.018(3)}\right)_{2} \mathrm{O}+0.13(1) \mathrm{Li}_{0.458(18)^{-}}$ $\mathrm{Ni}_{0.541(18)} \mathrm{O}$.

Cathode reactions of NiDL was investigated. Fig. 2 shows voltage curves during the first charge/discharge cycle and the

Table 1 Results of Rietveld refinement ${ }^{a}$

\begin{tabular}{|c|c|c|c|c|c|c|}
\hline Phase & $\begin{array}{l}\text { Space } \\
\text { group }\end{array}$ & $\begin{array}{l}\text { Lattice } \\
\text { parameters }(\AA)\end{array}$ & Atom & Site & $\begin{array}{l}\text { Occupancy } \\
(g)\end{array}$ & $\begin{array}{l}\text { Fraction } \\
\text { (mol\%) }\end{array}$ \\
\hline NiDL & $F m \overline{3} m$ & $a=4.6136(5)$ & $\begin{array}{l}\mathrm{Li} \\
\mathrm{Ni} \\
\mathrm{O}\end{array}$ & $\begin{array}{l}8 c \\
8 c \\
4 a\end{array}$ & $\begin{array}{l}g=0.947(9) \\
g=0.018(3)\end{array}$ & $87(1)$ \\
\hline
\end{tabular}

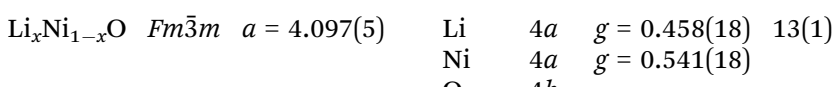

${ }^{a} R_{\mathrm{wp}}=3.36 \%, R_{\mathrm{p}}=2.64 \%, R_{\mathrm{e}}=2.34 \%, S=1.43$.

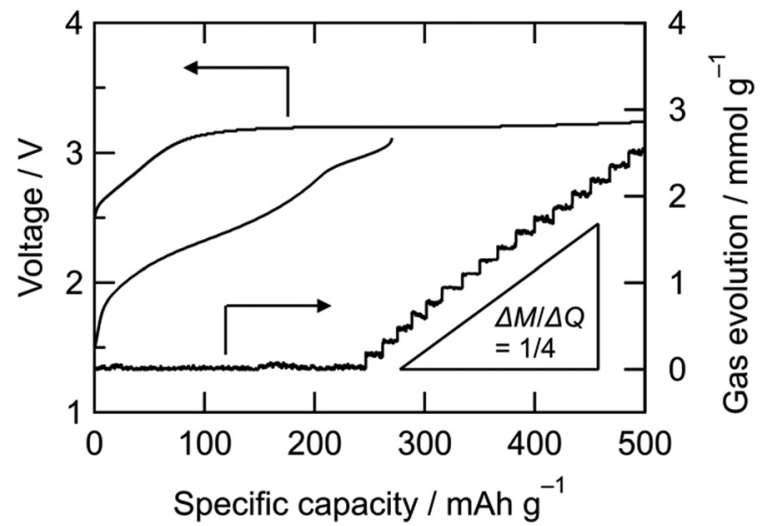

Fig. 2 Voltage curves and the amount of evolved gas of NiDL cathode. $M$ : amount of evolved gas, $Q$ : amount of transferred electrons.

amount of evolved gas during the first charge. The charge curve is divided into two regions: a slope at $2.5-3.2 \mathrm{~V}$ and a plateau at $3.2 \mathrm{~V}$. The former slope region showed that the Ni K-edge energy shifted to higher energy, which indicated the oxidation of Ni (Fig. 3a). On the other hand, little change in the edge energy was observed at the following plateau region, suggesting that oxidation other than Ni occurred. The gas evolution occurs over $250 \mathrm{~mA} \mathrm{~h} \mathrm{~g}^{-1}$ when charging; herein, $\mathrm{a} \frac{1}{4}$ gas evolution rate is achieved for every transferred electron, which indicates the occurrence of the following $\mathrm{O}_{2}$ evolution reaction:

$$
2 \mathrm{O}^{2-} \rightarrow \mathrm{O}_{2}+4 \mathrm{e}^{-}
$$

We confirmed an evolved gas as oxygen by in situ gas analysis using quadrupole mass spectrometer with TMDL cathode using Co as a dopant (see Section S5, ESI $\dagger$ ). Since structural and electrochemical properties are quite similar among TMDLs as shown below, the evolved gas in Fig. 2 is probably oxygen. The irreversibility of this reaction causes the specific capacity of NiDL to be restricted to less than $c a .250 \mathrm{~mA} \mathrm{~h} \mathrm{~g}{ }^{-1}$. However, by regulating the charge capacity to achieve a value of $270 \mathrm{~mA} \mathrm{~h} \mathrm{~g}^{-1}$, the subsequent discharge reaction occurred reversibly. Note that in the cathode material, the fraction of the $\mathrm{Li}_{x} \mathrm{Ni}_{1-x} \mathrm{O}$ phase is $19 \mathrm{wt} \%$. However, $\mathrm{Li}_{x} \mathrm{Ni}_{1-x} \mathrm{O}$ exhibits no redox plateaus, and its reversible capacity is $46 \mathrm{~mA} \mathrm{~h} \mathrm{~g}^{-1}$ (see Section S4, ESI $\dagger$ ); this value corresponds to only $8.7 \mathrm{~mA} \mathrm{~h} \mathrm{~g}^{-1}$ in the cathode material and the reversible capacity of $270 \mathrm{~mA} \mathrm{~h} \mathrm{~g}{ }^{-1}$ is due to NiDL. The discharge curve was divided into two regions: slopes at $3.1-2.8 \mathrm{~V}$ and 2.8-1.5 V. A slight shift in the Ni K-edge energy was observed at the former slope region, while a shift to lower energy was observed at the latter slope region (Fig. 3b). This indicates that the reduction of $\mathrm{Ni}$ occurs in the low voltage region. The redox reaction at the higher voltage was verified by investigating the $O$ K-edge X-ray absorption spectroscopy (XAS) analysis (Fig. 4). The O K-edge XANES spectra showed a peak at approximately $527.7 \mathrm{eV}$, which was not observed in $\mathrm{Li}_{2} \mathrm{O}$. This peak derived from $\mathrm{O} 2 \mathrm{p}$ electron holes (O) formed by hybridization with $\mathrm{Ni} 3 \mathrm{~d}$ orbitals. The strong hybridization of $\mathrm{Ni}$ and $\mathrm{O}$ is supported by firstprinciples band calculations (see Section S6, ESI†). In addition, its peak intensity increased after charging and decreased after 

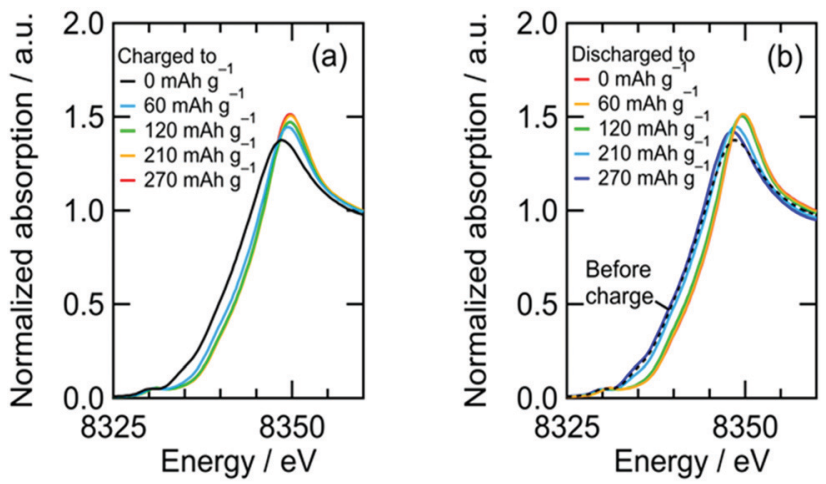

Fig. 3 Ni K-edge XANES spectra of NiDL cathode during charge/discharge.

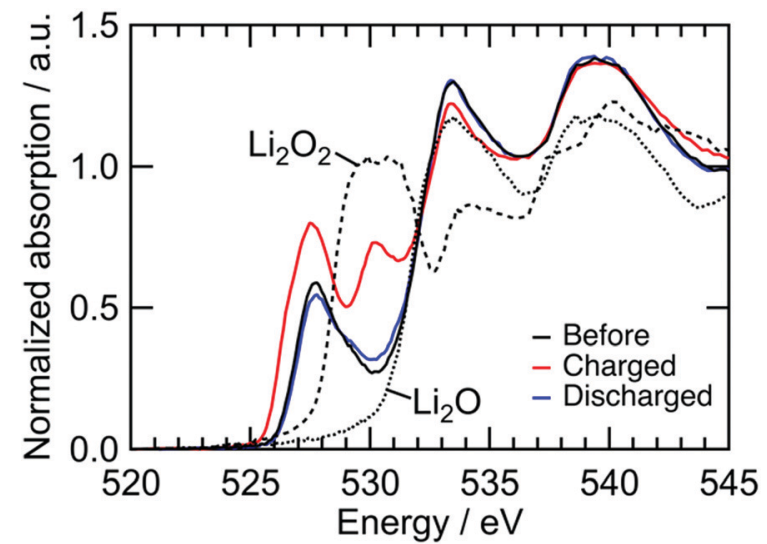

Fig. 4 O K-edge XANES spectra of NiDL cathode during charge/discharge.

discharging. This reversible change is caused by the Ni redox. Note that the Ni redox is cationic redox and formally $\mathrm{Ni}^{3+} / \mathrm{Ni}^{4+}$, but the redox should be appropriately expressed as the formation/ annihilation of $\mathrm{O}$ due to the strong hybridization of $\mathrm{Ni} 3 \mathrm{~d}$ and $\mathrm{O}$ 2 p orbitals. ${ }^{56}$ On the other hand, a peak at $530.2 \mathrm{eV}$ appeared and disappeared after being charged and discharged, respectively. This was caused by the formation/annihilation of $\sigma^{*}(\mathrm{O}-\mathrm{O})$ orbital. Therefore, the redox reaction at a higher voltage derives from the $\mathrm{O}^{2-} / \mathrm{O}_{2}{ }^{2-}$ redox reaction. The XAS analyses indicated that NiDL shows reversible cationic (formally $\mathrm{Ni}^{3+} / \mathrm{Ni}^{4+}$ ) and anionic $\left(\mathrm{O}^{2-} / \mathrm{O}_{2}{ }^{2-}\right)$ redox reactions.

\section{Universal solid-state oxygen redox with transition metal-doped lithium oxide}

Redox reactions of TMDL are similar between $\mathrm{Fe}-, \mathrm{Co}^{-}, \mathrm{Ni}-$, and $\mathrm{Cu}$-doped $\mathrm{Li}_{2} \mathrm{O}$ (i.e., FeDL, CoDL, NiDL, and CuDL, respectively). Fig. 5 shows the difference in spectra of $\mathrm{O}$ K-edge XANES before and after the charging process. O K-edge XANES spectra of FeDL, CoDL, and CuDL during the first charge/discharge cycle are shown in Fig. S10 (ESI $\dagger$ ). Two peaks are observed for each cathode at 525-529 eV and 529-535 eV, respectively. The former peaks are caused by the formation of $\mathrm{O}$ in the $\mathrm{O} 2 \mathrm{p}-\mathrm{TM} \mathrm{d}$ hybridized orbital. The peak positions differ in the dopant TM because the hybridized orbital has different energy levels. The latter peaks are caused by the formation of $\mathrm{O}_{2}{ }^{2-}$ species. The latter peak positions

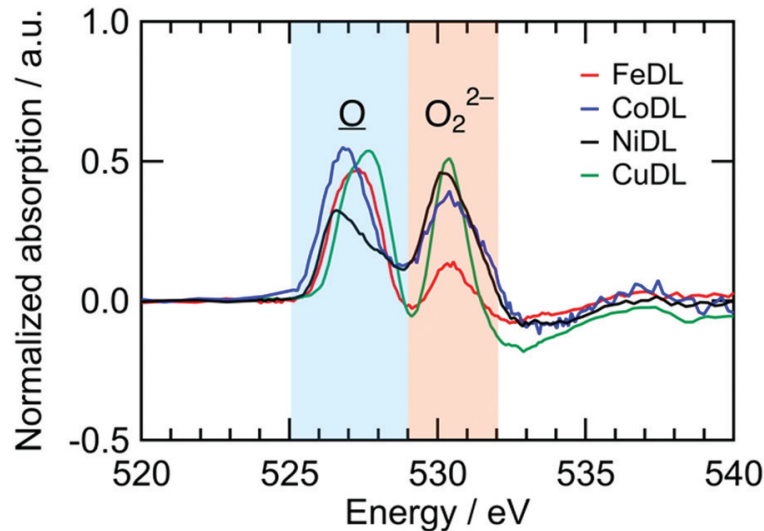

Fig. 5 Difference spectra of O K-edge XANES of TMDL cathodes before/ after charge.

are approximately similar ( $530.2 \mathrm{eV}$ ) regardless of the dopant TM. This analysis suggests that the doped TM probably does not contribute to the $\mathrm{O}^{2-} / \mathrm{O}_{2}{ }^{2-}$ redox; however, it contributes to the preceding $\underline{O}$ formation, which could catalyse the $\mathrm{O}_{2}{ }^{2-}$ formation.

These behaviours are indicated by the voltage curves (Fig. 6a). Diverse curves are observed in the region where the voltage increases (i.e., $\underline{\mathrm{O}}$ formation reaction) for different TMs, but similar $3.2 \mathrm{~V}$ plateaus (i.e., $\mathrm{O}_{2}{ }^{2-}$ formation reaction) were observed. The resulting discharge shows that the slopes at 3.1-2.8 $\mathrm{V}$ (i.e., $\mathrm{O}_{2}{ }^{2-}$ annihilation reaction) are approximately similar, except for the plateau length. This similarity substantiates the universal $\mathrm{O}^{2-} / \mathrm{O}_{2}{ }^{2-}$ redox characteristic of TMDLs.

However, cathode performances, such as cyclability, varied among TMDLs (Fig. 6b). CoDL and NiDL exhibited moderate cyclability with a specific capacity of $270 \mathrm{~mA} \mathrm{~h} \mathrm{~g}{ }^{-1}$. Whereas, FeDL showed a capacity loss during the primary cycles and a high coulombic reversible charge/discharge efficiency after ten cycles. This initial capacity loss in FeDL is probably caused by the difficulty with $\underline{O}$ annihilation (i.e., reduction of $\mathrm{Fe}^{4+}$ to $\left.\mathrm{Fe}^{3+}\right) \cdot{ }^{46}$ In the case of $\mathrm{CuDL}$, the discharge capacity gradually decreased during the charge/discharge cycles because of the decomposition of CuDL. This decomposition is mainly caused by Jahn-Teller distortion of $\mathrm{Cu}^{2+}$; tetrahedrally coordinated $\mathrm{Cu}$ in the $\mathrm{Li}_{2} \mathrm{O}$ structure can transform into $\mathrm{Li}_{2} \mathrm{CuO}_{2}$ with a square planar coordination via charge/discharge repetition. ${ }^{53}$ Considering cathode performances and the earth-abundance of dopant metals, NiDL is a promising cathode material. FeDL and CuDL can also be promising materials because of their earth abundance; however, this is possible only if cycle performances are improved. Recently, the cyclability of CuDL has been improved using fluorine doping. ${ }^{57}$ Doping other elements such as fluorine in cationic and anionic sites potentially can enhance the cathode performances of TMDLs. In addition, the surface modification of CoDL by vinylene carbonate or fluoroethylene carbonate shows excellent capacity improvement from 270 to $450 \mathrm{~mA} \mathrm{~h} \mathrm{~g}^{-1}$ while retaining its cyclability. ${ }^{50-52}$ Since TMDLs are basic and reactive with the electrolyte to decompose, such surface modification is also effective for enhancement of cathode performances. 

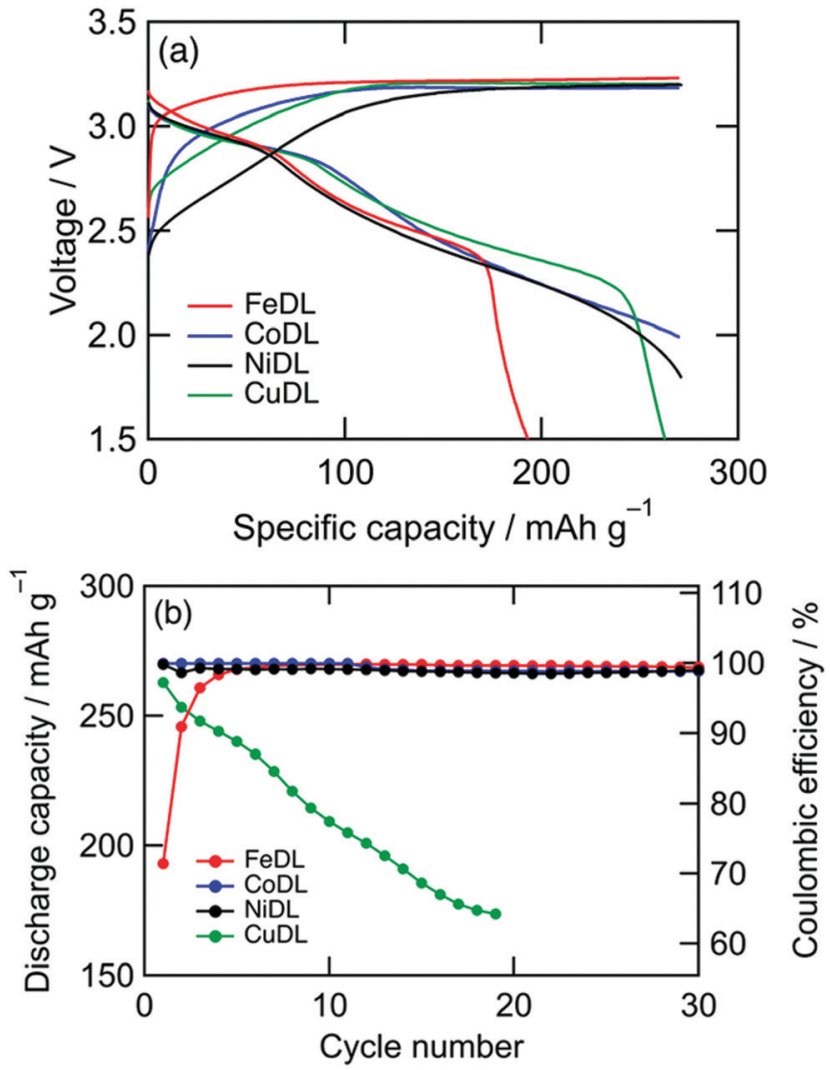

Fig. 6 (a) Voltage curves of TMDL cathodes during first cycle and (b) capacity retentions. Charge capacity was regulated to $270 \mathrm{~mA} \mathrm{~h} \mathrm{~g}^{-1}$. The plotted data correspond with both axes.

\section{Conclusions}

This study achieved a reversible solid-state oxygen redox in $\mathrm{Li}_{2} \mathrm{O}$ via the doping of transition metals such as Ni. The resulting reaction is universal for transition metal dopants. This reversible solid-state oxygen redox is probably activated by $\mathrm{O} 2 \mathrm{p}$ electron holes that are formed through hybridization with $\mathrm{d}$ orbitals of transition metals. However, cathode performances are observed to vary among different transition metals. Ni-Doping shows a significant promise for high-capacity cathode materials when considering the cathode performances and earth abundance of Ni.

\section{Experimental section}

The raw materials and as-obtained samples were handled in an Ar-filled glove box.

\section{Synthesis}

Powders of $\mathrm{Li}_{2} \mathrm{O}$ (Kojundo Chemical Laboratory Co., Ltd) and a transition metal (TM) source material were placed into a zirconia milling pot with yttria stabilized zirconia (YSZ) milling balls ( $3 \mathrm{~mm}$ diameter), and then pulverized using a planetary ball mill (Pulverisette 7, Fritsch) at $600 \mathrm{rpm}$ for $50 \mathrm{~h}$. As the TM source materials, $\mathrm{LiNiO}_{2}$ (FUJIFILM Wako Pure Chemical
Corp.), NiO (FUJIFILM Wako Pure Chemical Corp.), $\mathrm{LiFeO}_{2}$ (FUJIFILM Wako Pure Chemical Corp.), $\mathrm{LiCoO}_{2}$ (Strem Chemicals, Inc.), and $\mathrm{CuO}$ (Kanto Chemical Co., Inc.) were used. The atomic ratio of $\mathrm{TM} /(\mathrm{Li}+\mathrm{TM})$ was set to 10,9 , and $9 \%$ for $\mathrm{Fe}-, \mathrm{Co}-$, and $\mathrm{Cu}$-doped $\mathrm{Li}_{2} \mathrm{O}$, respectively, with reference to the previous reports. ${ }^{46,49,53}$

\section{Characterization}

Powder X-ray diffraction (XRD) patterns were recorded on a RIGAKU SmartLab system using monochromatized $\mathrm{Cu}-\mathrm{K} \alpha_{1}$ radiation. The sample was mounted on a gas-tight holder with a Be window under Ar. The Rietveld analysis was conducted using RIETAN-FP program. ${ }^{58} \mathrm{Ni}$ K-edge X-ray absorption nearedge structure (XANES) measurements were conducted using the transmission method at the BL-9C beamline of the Photon Factory in High Energy Accelerator Research Organization. Samples were sealed in an Al-laminated packaging film and attached to a sample holder. O K-edge XANES measurements were conducted using the fluorescence yield method at the BL-7A beamline. A sample holder was transferred to vacuum chambers using a transfer vessel filled with Ar. Ni K-edge and O K-edge XANES spectra were calibrated using Ni foil and Au foil, respectively, and analyzed using the Athena program. ${ }^{59}$ Scanning electron microscopy (SEM) images were obtained using Hitachi S-4700.

\section{Electrochemical measurements}

Samples were mixed with acetylene black (AB, Denka Co., Ltd) and polytetrafluoroethylene (Dupont-Mitsui Fluorochemicals) in a weight ratio of 45/50/5 and pressed on an $\mathrm{Al}$ mesh current collector to serve as the cathode. In order to elucidate the charge and discharge characteristics of the active material, the cathode contained sufficiently large amount of acetylene black for enough conductivity. The typical mass of active materials per area in the electrode was $5 \mathrm{mg} \mathrm{cm} \mathrm{cm}^{-2}$. For electrochemical tests, 2032-type coin cells were assembled with a Li metal foil as the anode, a glass filter (GA-55, ADVANTEC) as the separator, and $1 \mathrm{M} \mathrm{LiBF}_{4} /$ ethylene carbonate-diethyl carbonate $(1: 1$ by volume, Kishida Chemical) as the electrolyte. Charge/discharge tests were carried out at a constant current of $22.5 \mathrm{~mA} \mathrm{~g}^{-1}$ at $25{ }^{\circ} \mathrm{C}$. Gas evolution in a cell was confirmed by monitoring inner pressure change using a pressure gauge connected to the cell by a stainless steel tube and Swagelok ${ }^{\mathrm{TM}}$ fittings.

\section{Conflicts of interest}

There are no conflicts to declare.

\section{Acknowledgements}

This work was financially supported by JSPS KAKENHI Grant 19K15668, 15K18326, 17H03530 and 15H05797, JST ALCA-SPRING Grant Number JPMJAL1301, "Five-star Alliance," and Ensemble Grant for Young Researchers in Tohoku University Research Institutes. 


\section{References}

1 A. Grimaud, W. T. Hong, Y. Shao-Horn and J.-M. Tarascon, Nat. Mater., 2016, 15, 121.

2 M. Li, T. Liu, X. Bi, Z. Chen, K. Amine, C. Zhong and J. Lu, Chem. Soc. Rev., 2020, 49, 1688-1705.

3 M. Okubo and A. Yamada, ACS Appl. Mater. Interfaces, 2017, 9, 36463-36472.

4 B. Li and D. Xia, Adv. Mater., 2017, 29, 1701054.

5 N. Yabuuchi, Chem. Lett., 2017, 46, 412-422.

6 P. Kalyani, S. Chitra, T. Mohan and S. Gopukumar, J. Power Sources, 1999, 80, 103-106.

7 A. D. Robertson and P. G. Bruce, Chem. Mater., 2003, 15, 1984-1992.

8 M. Oishi, K. Yamanaka, I. Watanabe, K. Shimoda, T. Matsunaga, H. Arai, Y. Ukyo, Y. Uchimoto, Z. Ogumi and T. Ohta, J. Mater. Chem. A, 2016, 4, 9293-9302.

9 J. Rana, M. Stan, R. Kloepsch, J. Li, G. Schumacher, E. Welter, I. Zizak, J. Banhart and M. Winter, Adv. Energy Mater., 2014, 4, 1300998.

10 P. Yan, L. Xiao, J. Zheng, Y. Zhou, Y. He, X. Zu, S. X. Mao, J. Xiao, F. Gao and J.-G. Zhang, Chem. Mater., 2015, 27, 975-982.

11 J. Rana, J. K. Papp, Z. Lebens-Higgins, M. Zuba, L. A. Kaufman, A. Goel, R. Schmuch, M. Winter, M. S. Whittingham and W. Yang, ACS Energy Lett., 2020, 5, 634-641.

12 N. Guerrini, L. Jin, J. G. Lozano, K. Luo, A. Sobkowiak, K. Tsuruta, F. Massel, L.-C. Duda, M. R. Roberts and P. G. Bruce, Chem. Mater., 2020, 32, 3733-3740.

13 M. Sathiya, G. Rousse, K. Ramesha, C. Laisa, H. Vezin, M. T. Sougrati, M.-L. Doublet, D. Foix, D. Gonbeau and W. Walker, Nat. Mater., 2013, 12, 827-835.

14 M. Saubanère, E. McCalla, J.-M. Tarascon and M.-L. Doublet, Energy Environ. Sci., 2016, 9, 984-991.

15 M. Sathiya, K. Ramesha, G. Rousse, D. Foix, D. Gonbeau, A. Prakash, M. Doublet, K. Hemalatha and J.-M. Tarascon, Chem. Mater., 2013, 25, 1121-1131.

16 E. McCalla, A. M. Abakumov, M. Saubanère, D. Foix, E. J. Berg, G. Rousse, M.-L. Doublet, D. Gonbeau, P. Novák and G. Van Tendeloo, Science, 2015, 350, 1516-1521.

17 M. Sathiya, J.-B. Leriche, E. Salager, D. Gourier, J.-M. Tarascon and H. Vezin, Nat. Commun., 2015, 6, 1-7.

18 P. E. Pearce, A. J. Perez, G. Rousse, M. Saubanère, D. Batuk, D. Foix, E. McCalla, A. M. Abakumov, G. Van Tendeloo and M.-L. Doublet, Nat. Mater., 2017, 16, 580-586.

19 M. M. Thackeray, C. S. Johnson, J. T. Vaughey, N. Li and S. A. Hackney, J. Mater. Chem., 2005, 15, 2257-2267.

20 S. Hy, H. Liu, M. Zhang, D. Qian, B.-J. Hwang and Y. S. Meng, Energy Environ. Sci., 2016, 9, 1931-1954.

21 S. Zhao, K. Yan, J. Zhang, B. Sun and G. Wang, Angew. Chem. Int. Ed., 2020, DOI: 10.1002/anie.202000262.

22 P. Rozier and J. M. Tarascon, J. Electrochem. Soc., 2015, 162, A2490.

23 P. K. Nayak, E. M. Erickson, F. Schipper, T. R. Penki, N. Munichandraiah, P. Adelhelm, H. Sclar, F. Amalraj, B. Markovsky and D. Aurbach, Adv. Energy Mater., 2018, 8, 1702397.
24 N. Yabuuchi, M. Takeuchi, M. Nakayama, H. Shiiba, M. Ogawa, K. Nakayama, T. Ohta, D. Endo, T. Ozaki and T. Inamasu, Proc. Natl. Acad. Sci. U. S. A., 2015, 112, 7650-7655.

25 N. Yabuuchi, M. Nakayama, M. Takeuchi, S. Komaba, Y. Hashimoto, T. Mukai, H. Shiiba, K. Sato, Y. Kobayashi and A. Nakao, Nat. Commun., 2016, 7, 1-10.

26 M. Freire, N. V. Kosova, C. Jordy, D. Chateigner, O. Lebedev, A. Maignan and V. Pralong, Nat. Mater., 2016, 15, 173-177.

27 Z. Yao, S. Kim, J. He, V. I. Hegde and C. Wolverton, Sci. Adv., 2018, 4, eaao6754.

28 S. Narukawa, Y. Takeda, M. Nishijima, N. Imanishi, O. Yamamoto and M. Tabuchi, Solid State Ionics, 1999, 122, 59-64.

29 N. Imanishi, Y. Inoue, A. Hirano, M. Ueda, Y. Takeda, H. Sakaebe and M. Tabuchi, J. Power Sources, 2005, 146, 21-26.

30 A. Hirano, T. Matsumura, M. Ueda, N. Imanishi, Y. Takeda and M. Tabuchi, Solid State Ionics, 2005, 176, 2777-2782.

31 C. Johnson, S.-H. Kang, J. Vaughey, S. Pol, M. Balasubramanian and M. Thackeray, Chem. Mater., 2010, 22, 1263-1270.

32 K. Ding, L. Wang, J. Li, H. Jia and X. He, Int. J. Electrochem. Sci., 2011, 6, 6165-6176.

33 K. Ding, L. Wang, J. Li, H. Jia and X. He, Int. J. Electrochem. Sci., 2011, 6, 2859-2868.

34 K. Ding, L. Wang, J. Li, H. Jia and X. He, Int. J. Electrochem. Sci., 2012, 7, 1611.

35 L. Liang, J. Luo, M. Chen, L. Wang, J. Li and X. He, Int. J. Electrochem. Sci., 2013, 8, 6393-6398.

36 C. Zhan, Z. Yao, J. Lu, L. Ma, V. A. Maroni, L. Li, E. Lee, E. E. Alp, T. Wu and J. Wen, Nat. Energy, 2017, 2, 963-971.

37 L. Li, E. Lee, J. W. Freeland, T. T. Fister, M. M. Thackeray and M. K. Chan, J. Phys. Chem. Lett., 2019, 10, 806-812.

38 Z. Chen, Z. Zhang and J. Li, Phys. Chem. Chem. Phys., 2018, 20, 20363-20370.

39 D. Okuda, H. Kobayashi and M. Ishikawa, Solid State Ionics, 2020, 353, 115374.

40 D. Okuda, H. Kobayashi and M. Ishikawa, ACS Omega, 2020, 5, 16912-16918.

41 Z. Zhu, A. Kushima, Z. Yin, L. Qi, K. Amine, J. Lu and J. Li, Nat. Energy, 2016, 1, 1-7.

42 S. Y. Lee and Y. J. Park, Sci. Rep., 2019, 9, 1-10.

43 B. G. Lee and Y. J. Park, Nanoscale Res. Lett., 2019, 14, 378.

44 Y. Qiao, K. Jiang, H. Deng and H. Zhou, Nat. Catal., 2019, 2, 1035-1044.

45 S. Y. Lee and Y. J. Park, ACS Omega, 2020, 5, 3579-3587.

46 K. Harada, M. Hibino, H. Kobayashi, Y. Ogasawara, S.-i. Okuoka, K. Yonehara, H. Ono, Y. Sumida, K. Yamaguchi and T. Kudo, J. Power Sources, 2016, 322, 49-56.

47 S.-i. Okuoka, Y. Ogasawara, Y. Suga, M. Hibino, T. Kudo, H. Ono, K. Yonehara, Y. Sumida, Y. Yamada and A. Yamada, Sci. Rep., 2014, 4, 5684.

48 Y. Ogasawara, M. Hibino, H. Kobayashi, T. Kudo, D. Asakura, Y. Nanba, E. Hosono, N. Nagamura, Y. Kitada and I. Honma, J. Power Sources, 2015, 287, 220-225.

49 H. Kobayashi, M. Hibino, Y. Ogasawara, K. Yamaguchi, T. Kudo, S.-i. Okuoka, K. Yonehara, H. Ono, Y. Sumida and M. Oshima, J. Power Sources, 2016, 306, 567-572. 
50 H. Kobayashi, M. Hibino, Y. Kubota, Y. Ogasawara, K. Yamaguchi, T. Kudo, S.-i. Okuoka, H. Ono, K. Yonehara and Y. Sumida, J. Electrochem. Soc., 2017, 164, A750-A753.

51 T. Tsukasaki, M. Hibino, Y. Ogasawara, K. Yamaguchi, T. Kudo, S.-i. Okuoka, H. Ono, K. Yonehara, Y. Sumida and N. Mizuno, J. Electrochem. Soc., 2018, 165, A1971-A1974.

52 Y. Shimada, M. Hibino, Y. Ogasawara, K. Yamaguchi, T. Kudo, S.-i. Okuoka, H. Ono, K. Yonehara, Y. Sumida and N. Mizuno, Chem. Lett., 2018, 47, 776-779.

53 H. Kobayashi, M. Hibino, T. Makimoto, Y. Ogasawara, K. Yamaguchi, T. Kudo, S.-i. Okuoka, H. Ono, K. Yonehara and Y. Sumida, J. Power Sources, 2017, 340, 365-372.
54 I. Elias, A. Soon, J. Huang, B. S. Haynes and A. Montoya, Phys. Chem. Chem. Phys., 2019, 21, 25952-25961.

55 M. Obrovac, O. Mao and J. Dahn, Solid State Ionics, 1998, 112, 9-19.

56 Y. Uchimoto, H. Sawada and T. Yao, J. Power Sources, 2001, 97, 326-327.

57 Y. Shimada, H. Kobayashi, Y. Ogasawara, M. Hibino, T. Kudo, N. Mizuno and K. Yamaguchi, ACS Appl. Energy Mater., 2019, 2, 4389-4394.

58 F. Izumi and K. Momma, Solid State Phenom., 2007, 130, 15-20.

59 B. Ravel and M. Newville, J. Synchrotron Radiat., 2005, 12, 537-541. 